\title{
Late onset dominant cone dystrophy with early blue cone involvement
}

\author{
Loe N Went, Mary J van Schooneveld, Jendo A Oosterhuis
}

\begin{abstract}
A dominant cone dystrophy spanning seven generations was found in a pedigree from the Netherlands. The onset of the decline of visual acuity started after the age of 20 , while a near complete $a b-$ sence of blue cone function (a so-called tritan defect) already existed before the presence of any ophthalmological abnormalities.
\end{abstract}

Retinal receptor dystrophies comprise rod-cone dystrophies (usually retinitis pigmentosa), cone-rod dystrophies, and cone dystrophies. In the latter, the scotopic system, responsible for night vision, remains intact. Since conerod dystrophies will eventually lead to blindness, it is important to distinguish these conditions from cone dystrophies in which some visual function remains. The absence of rod involvement can be shown objectively with the help of the electroretinogram (ERG).

The mode of inheritance of inherited cone dystrophies is usually autosomal dominant but can be autosomal recessive or $\mathrm{X}$ linked. ${ }^{1-3}$ In most instances colour vision is impaired and progressive loss of visual acuity (VA) occurs within the first two decades of life. The colour vision disturbance is reported to be usually of the red-green type. ${ }^{1}$

In this article we present a family with a hitherto unreported form of cone dystrophy starting with blue cone involvement and with relatively late onset of visual loss. Preliminary results of the colour vision findings on this family were presented at the Tenth Symposium of the International Research Group on Colour Vision Deficiencies, June 1989, Cagliari, Sardinia, while the ophthalmological findings have been published elsewhere. ${ }^{4}$

\section{Department of} Human Genetics, Faculty of Medicine, University of Leiden, The Netherlands.

L N Went

The Netherlands Ophthalmic Research Institute, Amsterdam, The Netherlands. $M \mathrm{~J}$ van Schooneveld

Department of Ophthalmology, Faculty of Medicine, University of Leiden, The Netherlands. $\mathrm{J}$ A Oosterhuis

Correspondence to Dr Went, Terweeweg 142, 2341 CX Oegstgeest, The

Netherlands.

Received 26 June 1991 Revised version accepted 6 November 1991. curves 78 . The 'tritan test' was develo allow fast and specific screening for tritan defective persons, in contrast to the diagnostic
Ophthalmological methods, which we have described elsewhere, ${ }^{4}$ included measurement and fluorescein angiography. Colour Rand-Rittler the Ishihara and Har Lanthony desaturated panel D-15 (des D-15) arrangement tests, the 'Birch' plate test, ${ }^{5}$ the Nagel anomaloscope, the 'tritan test', ${ }^{6}$ and spectral sensitivity curve measurements which require some hours of strenuous observation. The 'tritan test' instrument has a one degree flickering (frequency $0.5 \mathrm{Hertz})$ blue $(462 \mathrm{~nm})$ test field on a 14 degree intense yellow background with a luminance of $3700 \mathrm{~cd} / \mathrm{m}^{2}$. The blue test field (luminance $1035 \mathrm{~cd} / \mathrm{m}^{2}$ ) may be attenuated with a neutral filter of density 2.6 or unattenuated. Tritan defective persons fail to see the attenuated stimulus, even after a long exposure, while normal subjects see it within 30 to 60 seconds of adaptation to the intense yellow light.

Family report

A pedigree of the family is reproduced in fig 1 and shows the classical pattern of autosomal dominant inheritance. The family history of the presumably affected subjects in generations II, III, and IV (photophobia and severe impairment of VA, starting gradually in adult life) is highly suggestive of the presence of the abnormal gene.

The index case (VI.6) was born in 1950. At the age of 12 corrected VA was 0.2 in the right eye (because of amblyopia) and 1.0 in the left; when 31 years old she had reading problems but VA of the left eye was still 0.9 . The ERG showed a normal rod response but a $50 \%$ decrease of amplitude in the cone response. The D-15 test showed a classical tritan response, in accordance with the almost complete absence of blue sensitivity on the spectral sensitivity curves (between 2 and 3 logarithms below the normal reading), and a tritan response with the 'tritan test'. She accepted a normal setting with the anomaloscope (proving the absence of a red-green defect), notwithstanding the fact that she could not distinguish any of the plates of the Ishihara and HRR tests. On testing this patient in September 1991 at the age of 41 , her VA was still unchanged (0.8). Her brother (VI.5), who was $1 \frac{1}{2}$ years older and who had a normal VA at the age of 18, at the age of 32 already had a severe decrease in VA and could count fingers only. The ERG showed a normal rod response and a decrease of the cone response to $25 \%$. He could not perform any of the colour vision tests.

In fig 2 the VA of the 13 affected subjects is plotted against age. Although there is considerable variation at a given age, visual loss has a tendency to start in the third or fourth decade, usually leading to a loss of central vision in the fourth or fifth decade. All subjects with a VA of 0.6 and lower had ophthalmological findings typical of cone dystrophy. 


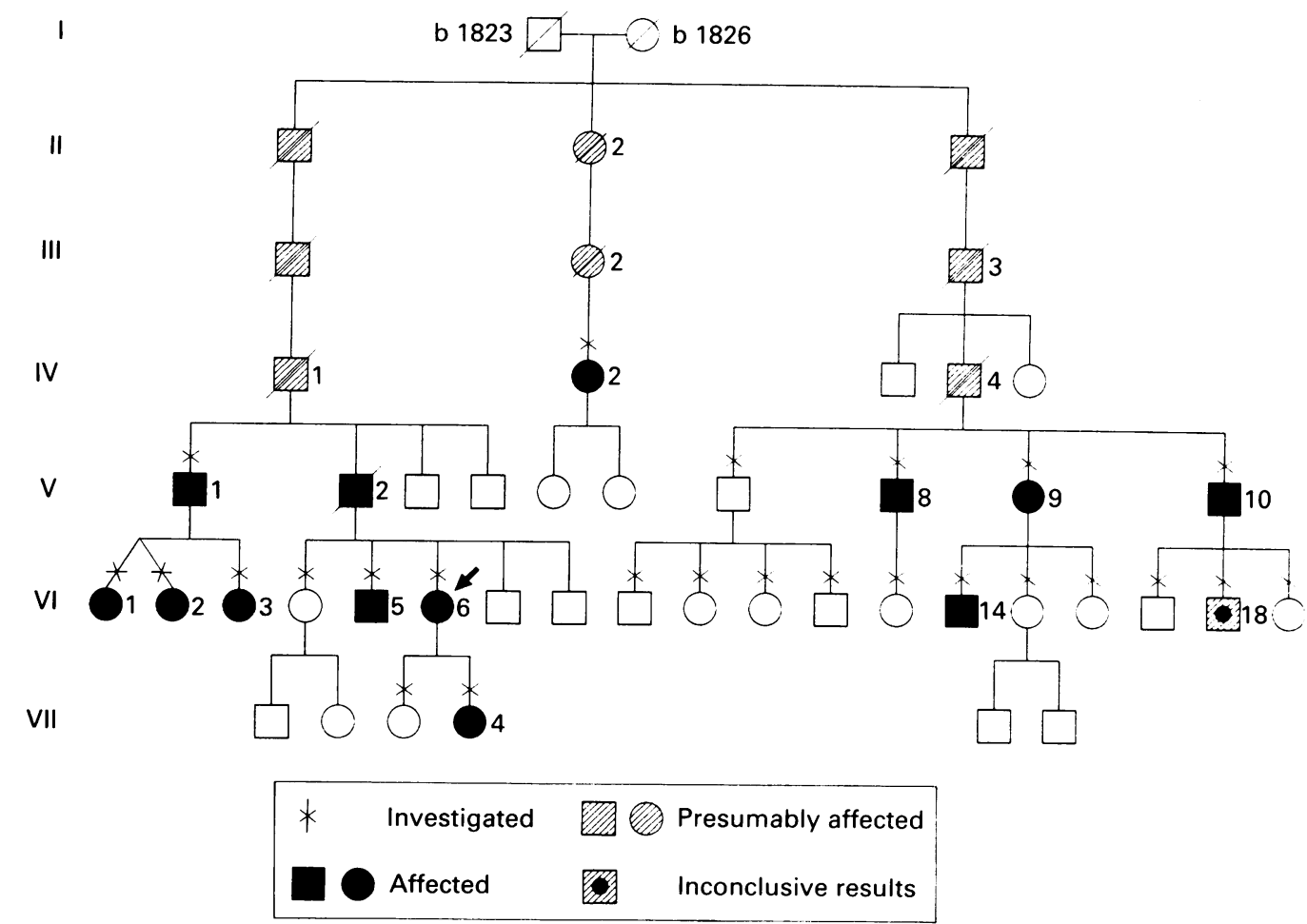

Figure 1 Pedigree of the family.

Fig 3 gives the spectral sensitivity curves of VI.2, who at that time (aged 28) had a VA of 0.8 with a reduced photopic ERG. The absence of the blue sensitive peak is evident, especially after bleaching with intense yellow light, which temporarily suppresses functioning of the red and green sensitive cones.

In six members of this family who had cone dystrophy (IV.2, V.1, V.2. V.8, V.9, and VI.5) colour vision studies were impossible owing to the low VA. In the other seven affected persons, the presence of the tritan defect was proven beyond doubt. Only in the case of VI.18, a not very cooperative boy aged 12 , could no reliable results be obtained.

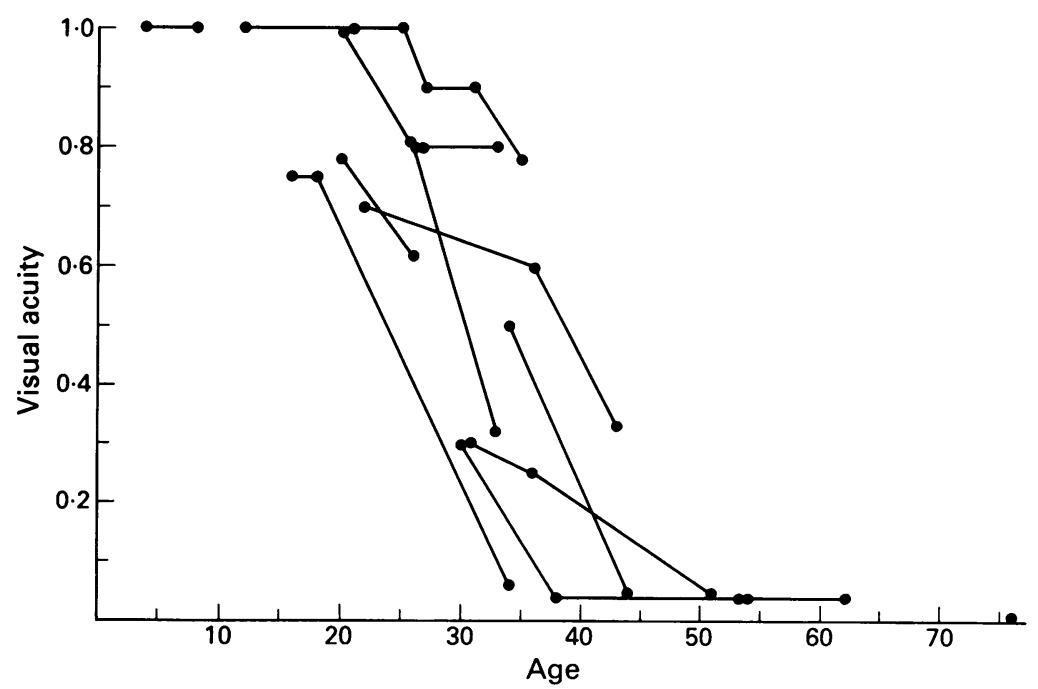

Figure 2 Visual acuity related to age in the 13 affected members of the family. Points connected by a line are measurements on the same patient at different ages.

\section{Discussion}

In our family the autosomal dominantly inherited cone dystrophy is associated with loss of blue cone function as an early sign. The diagnosis of cone dystrophy is firmly established by the characteristic symptoms: the abnormal fundus picture, loss of visual acuity, decreased or absent photopic ERG, and photophobia. We observed a normal fundus in seven patients; when maculopathy was visible, it presented mostly as diffuse pigment mottling. The progression of the pigmentary maculopathy was remarkably slow.

The severe impairment of blue cone function seems to occur before the onset of the decline of VA. Some patients even reported impaired blue-green discrimination from early childhood (IV.2, VI.3, and VI.5). In patient VI.14, who still had a normal photopic ERG at the age of 26 , defective blue cone function and a mild reduction of VA $(0.8)$ were the only obvious signs of the cone dystrophy. VII.4, who at the age of 13 had an entirely normal VA, made typical tritan errors with the Birch and HRR tests and failed the 'tritan test', while with the des D-15 she made some errors suggestive of a tritan defect (she performed the D15 correctly). She was too young for the spectral sensitivity curves.

The dizygotic twins VI.1 and VI.2 present further evidence for the variability of this dominant disorder. At the age of 26 both had a VA of $0 \cdot 8$, a normal appearance of the fundus, an abnormal photopic ERG, and classical tritan results with all colour vision tests (as exemplified in fig 3 for the spectral sensitivity curves of VI.2). At the age of 33 VI.2 still had retained her VA of 0.8 whereas in VI.1 it had 

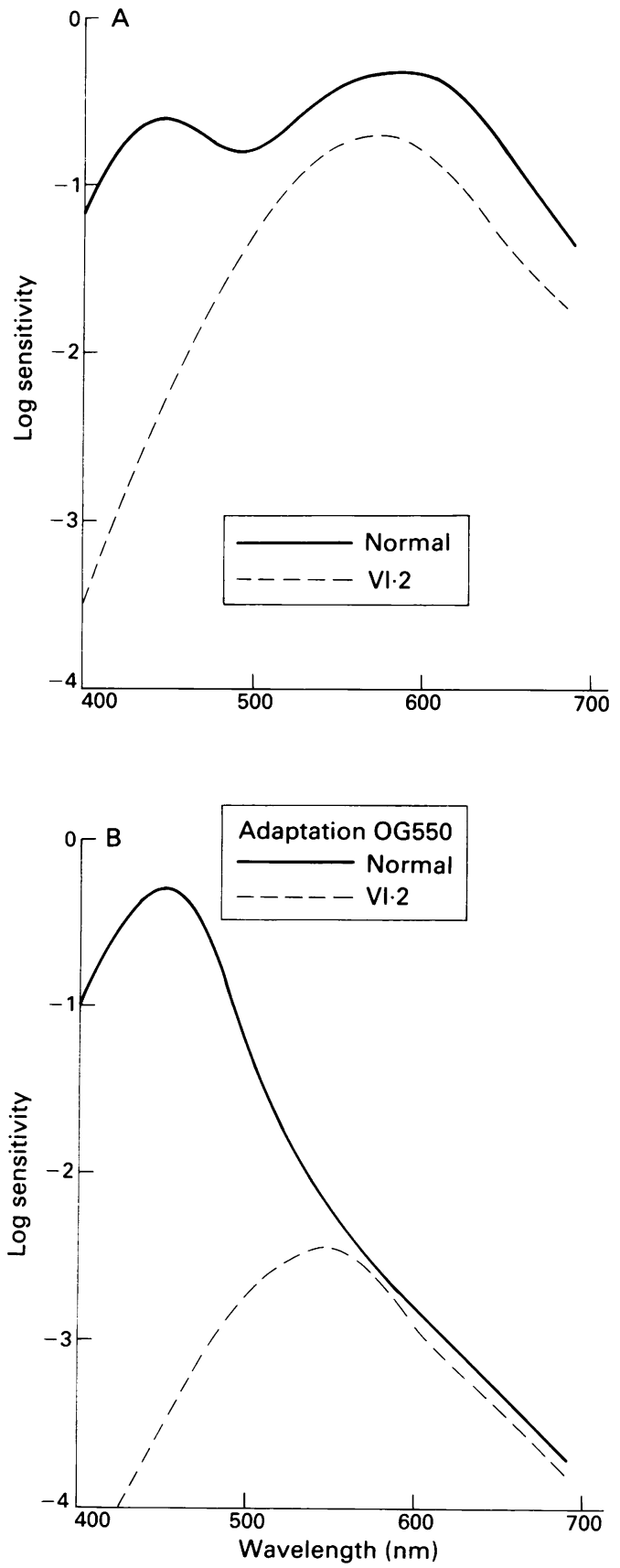

Figure 3 Spectral sensitivity curves of VI.2 compared with those of a normal subject. Top: normal white background (retinal illumination 3.9 log troland); bottom: yellow background (OG 550 filter, retinal illumination $5 \cdot 3$ log troland).

gone down to $0 \cdot 25$. The other ophthalmological findings had remained unchanged in both, including a normal fluorescein angiographic picture.

Marré et $a l^{9}$ observed blue-yellow and redgreen abnormalities in a pedigree with dominant cone dystrophy with a visual acuity already down to 0.3 at the age of 13 to 19 years. Weleber and Eisner ${ }^{1}$ stated that colour vision is usually normal until central vision begins to fail and, according to them, colour vision defects in most patients with cone degenerations are of the red-green type. In our family two patients (the index case VI.6 and VI.2), who failed or made numerous errors with the
Ishihara plates, chose a normal matching range with the anomaloscope, thus excluding a redgreen colour vision defect. Bresnick et $a l^{10}$ described a family with 'Autosomal dominant macular dystrophy with preferential shortwavelength sensitive cone involvement'. This title suggests that the condition in their family is comparable to the one we have described here. However, in contrast to our findings, their patients retained a good VA at mature age ( 1.3 in a 40 year old and 1.0 in a 36 year old patient); moreover, their photopic ERG was normal. Thus, their ophthalmological findings are different from ours but the tritan defect which they describe is closely comparable to the one present in our patients. It might be identical to the isolated but also dominantly inherited tritan disturbances reported in six families in the Netherlands by Went and Pronk. $^{8}$

Reichel et $a l^{11}$ have reported a 6.5 kilobase deletion within the red cone pigment gene on the $\mathrm{X}$ chromosome in a family with an $\mathrm{X}$ linked cone dystrophy accompanied by a loss of red cone function. Through discussions with Drs Weitz and Nathans from Baltimore, who found a likely mutation in four pedigrees with an autosomal dominant tritan defect, it seemed justified therefore to search for a comparable mutation in chromosome 7 in our family with a tritan defect and cone dystrophy. Dr Weitz kindly investigated DNA from a blood specimen of VI.2 from our family. He reports: "The blue-sensitive visual pigment locus was indistinguishable from that of normal controls by Southern blot and by denaturing gradient gel electrophoresis of 'GC-clamped' (Sheffield et al, Proc Natl Acad Sci USA 1989;86:232-6) polymerase chain reaction products containing the exons and adjoining non-coding sequences (Weitz and Nathans, unpublished observations). These results exclude any insertion or deletion larger than about 100 base pairs and make unlikely but do not exclude any smaller rearrangements or a point mutation within the gene" (C J Weitz, personal communication).

If one were to speculate that two separate genes, one for dominant cone dystrophy and one for a tritan defect, are responsible for the findings in our family these two genes would have to be extremely close since throughout the many steps between generations II to VII no segregation has occurred. Thus, the hypothesis of one single gene seems to be the most likely, a gene which appears not to have been described previously.

The figures are reproduced with the permission of the British fournal of Ophthalmo$\log y$ from figs 1,5 , and 6 in the article in reference 4 .

1 Weleber RG, Eisner A. Cone degeneration ("bull's eye dystrophies") and color vision defects. In: Newsome DA, Raven Press, 1988;154:162,233-56.

2 Gouras P, Eggers HM, MacKay CJ. Cone dystrophy, nyctalopia and supernormal rod responses. Arch Ophthalmol 1983;101:718-24.

3 Keunen JEE, van Everdingen JAM, Went LN, Oosterhuis $\mathrm{JA}$, van Norren D. Color matching and retinal densitometry in patients and carriers of an X-linked progressive 
4 van Schooneveld MJ, Went LN, Oosterhuis JA. Dominant cone dystrophy starting with blue cone involvement. $\mathrm{Br} \mathcal{F}$ Cone dystrophy starting with

5 Birch-Cox J. Design of diagnostic test for congenital and acquired colour vision defects. In: Verriest G, ed. Colou vision deficiencies. 4th ed. Basel: Karger, 1976;196-201.

6 van Norren D, Went LN. New test for the detection of tritan defects evaluated in two surveys. Vision Re $1981 ; 21: 1303-6$

7 de Vries-de Mol EC, Went LN, van Norren D, Pols LCW Increment spectral sensitivity of hemizygotes and heterozygotes for different classes of colour vision. Mod Prob Ophthalmol 1978;19:224-8.

8 Went LN, Pronk N. The genetics of tritan disturbances. Hum Genet 1985;69:255-62.
9 Marré M, Marré E, Zenker H-J, Fülle D. Colour vision in a family with dominant progressive cone dystrophy. In Marré $\mathrm{E}$ Tostand $\mathrm{M}$, Zenker $\mathrm{H}-\mathrm{J}$, eds. Normal and pathologic colour vision. Halle: Martin Luther Universität, pathologic colour vision. Halle: Martin Luther Universitat,

10 Bresnick GH, Smith VC, Pokorny J. Autosomal dominantly inherited macular dystrophy with preferential short wavelength sensitive cone involvement. Am f Ophthalmo

11 Reichel E, Bruce AM, Sandberg MA, Berson EL. An electroretinographic and molecular genetic study of $\mathrm{X}$-linked cone degeneration. Am $f$ Ophthalmol 1989; 108:540-7. 